\title{
Study on the Current Situation and Optimization Strategy of Risk Measurement in International Trade Burenmende
}

School of economics and management, Inner Mongolia University for the Nationalities, Tongliao, 028000, China

Keywords: International trade; risk measurement; current situation; optimization strategy

\begin{abstract}
Risk measurement in international trade plays an important role in the development of the international trade risks, which can effectively evaluate the possibility of risk occurrence, provides a scientific basis for the risk prevention in the projects of international trade, so that to effectively avoid risks. In this paper, it mainly studied on the current situation and optimization strategy of risk in international trade.

With the development of market economy, the transaction risks in the international trade intensified, so in order to effectively avoid the risk in international trade, the risk management of international trade should be conducted to promote the growth of the enterprise economy. The risk management of international trade includes risk assessment, identification of winnowing, and risk prevention, etc. The risk measurement in international trade is an important job after the identification of risk, which can effectively evaluate the possibility and other aspects of risk occurrence, and is of great significance to the development of enterprise economy.
\end{abstract}

\section{Current Situation of Risk Measurement in the International Trade}

Currently, the risk measurement in international trade is an important means for the enterprise to prevent the risk in international trade, and as the core content of risk management in international trade, it plays an important role in avoiding risks. The followings are detailed analysis on the current situation of risk measurement in international trade.

1.1 The understanding of enterprise on the risk measurement work in international trade is not enough

Due to an international trade project contains a variety of risks, and those risks compose the total risks in international trade, therefore, if the enterprise want to effectively avoid risks, they not only need to analyze the total risks of international trade detailedly, but also need measure each trade risk in the work of trade risk; however, the leaders of some enterprises in China have poor understandings on the risk measurement work in international trade, and they think that trade risk can only be used in risk assessment and is unable to fully implement its value in the enterprise, while such wrong idea often leads to the loss of the enterprise. Actually in the practical work, the risk work in international trade can measure not only the possibility of risk occurrence, the seriousness of the consequences of risk, and the occurrence time of risk events, but also the subjective feeling ability of the risk in international trade.

1.2 The angle of risk measurement is singleness.

At present, the angle of risk measurement is singleness, and this an important problem in the work of risk measurement in international trade. In some enterprises in China, there are usually some common faults, such as the singleness measurement standard and insufficient dimension of the risk in international trade, and the incomplete consideration of the risk work in international trade, etc. Due to the above reasons, the enterprise cannot accurately measure the risk state in international trade, which makes the enterprise cannot avoid the risk effectively, and brings certain losses to the enterprise.

1.3 Less reference factors for the risk measurement

When conducting the risk measurement in international trade, it must refer to some important factors, such as the risk data, risk identification report, and types of international trade project, etc. Among them, the risk data includes risk prevention summary, historical record of risk occurrence, 
and the enterprise often conduct the risk measurement in international trade according to the risk data. While risk identification refers to the existence of risk symptoms in the international trade transaction, as well as the analysis of reason, background and nature of risk occurrence, etc. Therefore, due to the risk in international trade can only be measured by the enterprise accurately based on the above reference factors, but in actual work, the reference factors for the enterprises are too little, so they cannot fully consider the influence of the risk in international trade for them. Especially, the lack of consideration to the management goal and strategy of the enterprise makes the enterprise cannot reach the management goal, thus do harm to the fundamental interests of the enterprise.

1.4 The focus of risk measurement in international trade is not clear

Due to there are some risks in the international trade risk, so the enterprise must clear the focus of the risk measurement in international trade to make the enterprise avoid risks effectively, but for some enterprises in China, the focus of risk measurement in international trade is not clear enough. They often spend a lot of time and energy to study the trade risk which only has a small impact on the enterprise, and ignore the measurement towards the major potential risks, thus it can be seen that to clear the focus of the risk measurement plays an important role in avoiding risks for the enterprise.

1.5 No reasonable adoption for the methods of risk measurement in international trade

Different risks in international trade need to adopt different methods of risk measurement in international trade, but many enterprises in our country have unreasonable choices for the methods of risk measurement in international trade, and they don't choose the appropriate methods of risk measurement in international trade according to the specific situation, which greatly reduces the efficiency of risk measurement in international trade, cannot accurately measure the risks in international trade, and brings certain loss of benefits for the enterprise.

1.6 Unable to be strictly in according with the program of risk measurement in international trade

Because the crisis level of risk occurrence for the enterprise is different, so the degree of the risk measurement in international trade also has a certain difference, and the staff should measure the risks in international trade according to the different crisis level and the strength of harmfulness, and according to the correct and reasonable program. But in fact, when some enterprises have risks, they will conduct the same program without choosing appropriate measurement program due to the different crisis level of risks in international trade, which has a great impact on the enterprise.

1.7 The lack of professional staff of risk measurement in international trade

At present, the professional talent plays an important role in the development of the enterprise, and even relates to the survival and development of the enterprise, but some enterprises in China are lack of professional talent of risk measurement in international trade, and the staff of risk measurement in some enterprises is not only lack of professional knowledge, but also lack of the certain experience of risk measurement in international trade. While the overall quality of those staffs is low, and most of them are more familiar with risk assessment, but are lack of the understanding of the work of risk measurement in international trade, thus in the process of measuring the risk in international trade, they cannot accurately measure the risk in international trade, which greatly reduces the efficiency of the risk measurement in international trade, and hinders the development of the enterprise economy.

\section{Optimization Strategy of the Risk Measurement in International Trade}

2.1 To strengthen the understanding of the risk measurement in international trade for the enterprise

Strengthening the understanding of the risk measurement in international trade for the enterprise is a important way to optimize the risk measurement in international trade, so the leaders should firstly have a fully understanding on the importance of risk measurement work in international trade, and change the original old ideas, leading to business leaders to pay attention to the risk measurement work in international trade. This is the premise to achieve the risk measurement in 
international trade. Secondly, the enterprise should adopt the appropriate method of propaganda, and strengthen the staff's understanding of risk measurement work, so that to allow them better develop the value of risk measurement work in international trade, and bring more economic benefits for the enterprise.

2.2 Carry out the risk measurement work in international trade from the different dimensions and scales

Due to the risk factors in international trade is composed by various kinds of factor risks, and the risk situation also presents a big difference, so when measuring the risk in international trade, it should be conducted from different dimensions and scales to make the risk measurement work in international trade accurately. Therefore, when the enterprise carries out the risk measurement work in international trade, it must have a comprehensive consideration on the risk factors.

2.3 Reasonably refers to the basis of the risk work of international trade

To achieve the risk assessment, it should refer to some important factors, so that to make the result of risk assessment more accurately. The reference factors of risk measurement work in international trade include the report of risk identification, risk data, specific types of international trade projects, and the management goals and strategies of the enterprises, etc. For the risk data, it is the precondition of the risk measurement, so when conducting the risk assessment, it must use it as an important reference factor. Risk data includes risk prevention summary, historical record of international trade occurrence, and when measuring the risk in international trade, it must refer to it comprehensively, while in the report of risk identification, it contains the detailed descriptions of risk symptoms, signs, and the reasons and backgrounds of risk occurrence, which has a great reference value for the risk measurement in international trade. In addition, when measuring the risk projects in international trade, it should consider the types of international trade projects, and due to the risk of international trade project is higher, so it should be focused on. Therefore, taking these factors as the reference basis of risk measurement work in international trade makes the risk measurement more accurate.

2.4 Clear the focus of risk measurement in international trade

To clear the focus of risk measurement in international trade firstly needs the staff to measure the crisis level of risks, and divide the international trade risk into two categories, one is the risk with great crisis level and the other is the risk with small crisis level. Foe the international trade risk with great crisis level, the staff should focus on the analysis and research, and for the small crisis level, there is no impact on the enterprise, so the enterprise does not need to research in-depth, which can greatly save the time and energy of the related staff, and improve the efficiency of the risk work in international trade.

2.5 Choose appropriate method of the risk measurement in international trade

Different international trade risk should choose the appropriate methods of risk measurement in international trade; for example, the staff of risk measurement is familiar with the export business, as well as the transaction risk of international trade, so the determination of risk in international trade should adopt the methods of subjective probability inference. The probability of international trade risk mainly depends on the way to affirm the subjective consciousness, and depends on the understanding of some international trade risk. If the foreign trade staff has an enough understanding on the trading market and transaction object, it can adopt the method of statistics. To determine the possibility of risk occurrence according to the data arranged by the measurement staff, and to sum up the information in the data have great uses for assessing the risk of international trade. When the staff simulates the distribution of the state of risk probability, it can adopt the method of the theory probability, and this method often firstly studies the regulation of risk occurrence, and then studies the probability distribution of international trade risk through the mathematical model. Choosing the appropriate method of risk measurement in international trade can improve the efficiency of risk measurement work and help the staff to reduce workload.

2.6 Strictly in accordance with the program of risk measurement in international trade

In strict accordance with the program of risk measurement in international trade is the precondition to ensure the risk measurement work in international trade accurately. The program of 
risk measurement in international trade includes five aspects, namely are making risk measurement plan, preparing the materials of risk measurement work, measuring the international trade risk, risk measurement report and reporting the result of risk measurement. The management staff must strictly follows the above five aspects, and after completing the risk measurement, they should submit the report of risk measurement timely, and report the result of risk measurement to the management department of international trade enterprise in detail. After that, the staff of risk management should evaluate the risk according to the result of risk measurement, determine the level of each risk, develop the sequence table of international trade risk, timely put forward international trade risk needed to be mainly prevented, and formulate corresponding measures to prevent the occurrence of risk according to the result of risk measurement.

2.7 Cultivate professional staff for the risk measurement in international trade

Due to the risk measurement work in international trade plays an irreplaceable role in the enterprise, so the staff of risk measurement in international trade needs to accurately infer the possibility of risk occurrence, the reasons and influences of risk occurrence, which greatly improve the requirements of the enterprise towards the talent of risk measurement in international trade. Therefore, in order to cultivate professional talent of risk measurement in international trade and meets the requirements of enterprise towards measurement staff, firstly the enterprise should train the staff related to risk measurement, strengthen the professional knowledge of the staff, and at the same time, arrange the best experienced staff to teach relevant knowledge of risk measurement; secondly, the enterprise should establish and perfect the system of assessment, and arrange the management team to make regularly evaluation towards the related risk measurement staff. Only the staff that is qualified in the assessment can go to work, and the staff with excellent assessment should give a certain reward. Finally, the enterprise should strengthen the staff's overall quality of risk measurement, and cultivate the responsibility and service consciousness of the risk measurement staff.

\subsection{Reasonable utilization of the results of risk measurement}

The result of risk measurement plays an important role in the risk management of the enterprise, so the enterprise must reasonably use the result of the risk measurement, and help the enterprise to effectively avoid the trade risk. The result of risk measurement can be the key factor for the enterprise to avoid risk, and can be the basis to prevent the international trade risk. Through the analysis of the result of international trade risk, we can know which risk we can afford and which we can not afford and must be avoided and transferred, and we can determine which risk we should focus on to prevent and which risk we must focus on managing. At the same time, according to the result of risk measurement, we can determine the size of the hazard of the risk, and determine the focus of the risk management and the disposal methods towards the risk. Additionally, according to the result of international trade risk, we can also determine whether the foreign trade project is worthwhile to implement and to take corresponding measures to prevent risks according to the result of risk measurement. The result of risk measurement can also provide the basis for the foreign trade management strategy, and makes the enterprise to make the right transaction decisions in the process of foreign trade; therefore, it must use the result of risk measurement reasonably to make the enterprise to be able to solve all kinds of risks in foreign trade.

\section{Conclusion}

To sum up, the risk measurement in international trade plays an important role in the development of the enterprise, which can provide effective scientific basis for risk evaluation, and provide some strategic measures for the business strategy of the trade. According to the result of international trade, our country can effectively solve the harmfulness of international trade risk. But at the present stage, our risk measurement in international trade still has many shortcomings. The author thinks that it needs to improve the existing problems in the risk measurement of international trade in time, to continuously improve the risk measurement in international trade, and to control the risk in the international trade project, so that to make the business leaders to make correct decisions in the project of international trade. The future risk measurement work in international 
trade will bring more economic benefits for the enterprise, as will as to promote the continuous development of foreign trade in China.

\section{References}

[1] Xie Fei, Study on the Exchange Rate Risk Measurement and Avoidance in the International Trade of Enterprise under the Uncertain Conditions [D], Chongqing University, 2009.

[2] Wu Jiangong, On the Cultivation of the Ability of Preventing International Trade Risks [J], High Education Forum, 2009, 12: 12-16

[3] Wu Haobo, Relationship between the International Trade Terms and International Trade Risk [J], Cuide to Business, 2010, 01: 161-162.

[4] Zhang Dian, Ke Sheng, Yang Chao, On the Cultivation of the Ability of Preventing International Trade Risks [J], China Economic \& Trade Herald, 2010, 06: 43.

[5] Gao Haiyu, Relationship between the International Trade Terms and International Trade Risk [J], Modern Economic Information, 2011, 06:110. 